\title{
The effect of supplementation with different oil emulsions on energy intake and body weight - the results of two different studies
}

\author{
C. J. Harden ${ }^{1,2,3}$, V. Dible ${ }^{1}$, M. E. Barker ${ }^{1}$, N. J. Hepburn ${ }^{4}$, I. Garaiova ${ }^{4}$, \\ S. F. Plummer ${ }^{2}$ and B. M. Corfe ${ }^{1}$ \\ ${ }^{1}$ Molecular Gastroenterology Research Group, Academic Unit of Surgical Oncology, Department of Oncology, The \\ University of Sheffield, Sheffield, S10 2RX, ${ }^{2}$ Cultech Ltd., Unit 3, Christchurch Road, Port Talbot, West Glamorgan, SA12 \\ 7BZ, ${ }^{3}$ Centre for Food Innovation, Sheffield Hallam University, Sheffield, S1 1WB and ${ }^{4}$ Obsidian Research Ltd., Unit 2, \\ Christchurch Road, Port Talbot, West Glamorgan, SA12 7BZ, UK
}

The presence of fat in the small intestine and its subsequent digestion into free fatty acids slows gastric emptying, stimulates gastrointestinal hormone release and suppresses appetite and energy intake ${ }^{(1)}$. Lipids vary substantially in fatty acid composition, chain length and degree of saturation so may not all elicit the same respons $\mathrm{e}^{(2)}$. The differential effects of long chain fatty acids on energy intake and body weight are not comprehensively understood ${ }^{(3)}$. This study aimed to investigate the effect of omega-3-rich and -poor emulsions on subsequent energy intake.

A controlled, crossover intervention using normal and overweight males $(n=18)$ was conducted to examine 24-hr energy intake after two different $45 \%$ oil-in-water emulsions of (docosahexaenoic acid) DHA and oleic acid (OA), compared to no treatment (NT). Energy intake was $12,097 \mathrm{~kJ}$ after NT, 9,912 kJ after OA and 8,539 kJ after DHA. The difference between DHA and NT was statistically significant (Table 1).

A double-blind, randomised controlled parallel trial was conducted to examine the effects of DHA consumption over twelve weeks compared to OA on energy intake and body weight. Overweight and obese females $(n=40)$ consumed either emulsion before lunch and evening meal for twelve weeks. Mean body weight $(\mathrm{kg})$ was significantly reduced by $3.5 \%$ in the DHA group compared to $1.1 \%$ in the OA group $(P=.037)$. Body mass index $\left(\mathrm{kg} / \mathrm{m}^{2}\right)$ was significantly reduced by $3.9 \%$ in the DHA group compared to $1.9 \%$ in the OA group $(P=.032)$. There was no effect of treatment on body composition. Differential reduction in energy contribution between macronutrient groups was noted (Table 2).

Table 1. Results of the acute feeding experiment

\begin{tabular}{lrrr}
\hline & \multicolumn{2}{c}{ Energy $(\mathrm{kJ})$} & \\
\cline { 2 - 4 } Treatment & Mean & SD & $p=$ \\
\hline NT & $* 12,097$ & $(5,429)$ & \\
OA & 9,912 & $(2,733)$ & $\mathbf{0 . 0 4 8}$ \\
DHA & $* 8,539$ & $(2,720)$ & \\
\hline
\end{tabular}

* Post hoc tests indicate mean energy intake for NT was significantly $(P=.039)$ different from DHA.

Table 2. Results of the 12 week intervention presented as change from baseline

\begin{tabular}{|c|c|c|c|c|c|}
\hline \multirow[b]{4}{*}{ Measurement } & \multicolumn{4}{|c|}{ Treatment Type } & \multirow[b]{4}{*}{$p=$} \\
\hline & & & & & \\
\hline & \multicolumn{2}{|c|}{ Change from baseline } & \multicolumn{2}{|c|}{ Change from baseline } & \\
\hline & Mean & SD & Mean & SD & \\
\hline Body weight (kg) & -3.24 & 1.93 & -1.66 & 1.25 & 0.037 \\
\hline BMI $\left(\mathrm{kg} / \mathrm{m}^{2}\right)$ & -1.38 & 0.94 & -1.66 & 1.25 & $\mathbf{0 . 0 3 2}$ \\
\hline Energy (kJ) & $-2,514$ & 1,979 & -531 & 1,594 & 0.020 \\
\hline Protein $(\mathrm{g})$ & -12 & 18.8 & -3.4 & 13.7 & 0.320 \\
\hline Carbohydrate (g) & -63.3 & 56.3 & -22.1 & 50.0 & $\mathbf{0 . 0 3 7}$ \\
\hline Fat $(\mathrm{g})$ & -26.8 & 22.9 & -5.5 & 23.1 & 0.045 \\
\hline Saturated fat $(\mathrm{g})$ & -9.9 & 7.0 & -1.6 & 7.8 & 0.021 \\
\hline
\end{tabular}

In two human feeding studies, DHA consumption significantly reduced total daily energy intake in comparison with isocaloric dosing of a non-omega-3-rich preparation. These data suggest that position of desaturation may play a role in the regulation of appetite by lipids.

1. Little TJ, Russo A, Meyer JH et al. (2007) Gastroenterology 133, 1124-1131.

2. McLaughlin J (2007) Biochem Soc Trans 35, 1199-202.

3. Li JJ, Huang CJ \& Xie D (2008) Mol Nutr Food Res 52, 631-645. 